\title{
The Communicative Ability of Universiti Teknologi MARA
}

\section{Sarawak's Graduates}

\author{
Sharifah Zakiah Wan Hassan \\ Universiti Teknologi MARA SARAWAK, Jln Meranek, 94300 Kota Samarahan, Sarawak, Malaysia
}

Tel: 60-82-677-683 E-mail: shzakiah@sarawak.uitm.edu.my

Simon Faizal Hakim

Universiti Teknologi MARA SARAWAK, Jln Meranek, 94300 Kota Samarahan, Sarawak, Malaysia

Tel: 60-82-677-593 E-mail: spbotley@sarawak.uitm.edu.my

Mahdalela Rahim

Universiti Teknologi MARA SARAWAK, Jln Meranek, 94300 Kota Samarahan, Sarawak, Malaysia

Tel : 60-82-677-524 E-mail: mahdalela@sarawak.uitm.edu.my

John Francis Noyem

Universiti Teknologi MARA SARAWAK, Jln Meranek, 94300 Kota Samarahan, Sarawak, Malaysia

Tel: 60-82-677-596 E-mail: jnoyan@sarawak.uitm.edu.my

Sueb Ibrahim

Universiti Teknologi MARA SARAWAK, Jln Meranek, 94300 Kota Samarahan, Sarawak, Malaysia

Tel: 60-82-677-699Ｅ-mail: ebraiz@sarawak.uitm.edu.my

Johnny Ahmad

Universiti Teknologi MARA SARAWAK, Jln Meranek, 94300 Kota Samarahan, Sarawak, Malaysia

Tel: 60-82-677-703 E-mail: johnny@sarawak.uitm.edu.my

\begin{abstract}
Kamaruzaman Jusoff (Corresponding author)
Tropical Forest Airborne Observatory (TropAIR), Faculty of Forestry, Universiti Putra Malaysia, 43400 Serdang, Selangor. Malaysia
\end{abstract}

Tel: 60-3-8946-7176 E-mail: kjusoff@yahoo.com

\begin{abstract}
This study explores Universiti Teknologi MARA (UiTM) Sarawak graduating students' oral proficiency, focusing on grammatical accuracy. Oral proficiency in English has always been the benchmark of language proficiency, and in the context of UiTM's language teaching curriculum, efforts to enhance students' oral proficiency are implemented through various languages proficiency-based and ESP courses. A small corpus of group discussions was analysed to identify and classify grammatical errors and other performance factors in students' oral communication. The analysis was carried out using text analysis software used in corpus linguistics (Dagneaux et al, 1998, Scott, 1996). The software was used to classify grammatical errors into general categories such as grammar, word, lexical, formal, style, lexico grammar and register. It was found that the students who took part in group discussions displayed frequent lexical, grammatical and formal errors. Also there was much evidence of performance phenomena such as hesitation, repetitions, incomplete structures and redundancy. This provides evidence that, despite many years of ESL input, some UiTM graduating students still seem to require a great deal of practice with basic grammatical structures. The practical implications derived from the findings of the study suggest that teachers and curriculum developers ought to help students develop
\end{abstract}


their proficiency in English language learning by giving them ample opportunity to use, produce and practice English language structures or sentences through simulated situations in various immersion activities in class and outside the classroom as well as introducing consciousness-raising techniques to sensitise learners to the various forms and meanings of structures used in everyday conversation in English.

Keywords: Graduating students, Oral proficiency, Grammatical accuracy

\section{Introduction}

Universiti Teknologi MARA Malaysia (UiTM) is one of the nation's rising tertiary institutions with 'an international reach', and is in fact the largest university in Malaysia. UiTM is currently on the move to be one of Malaysia's premier universities with world class status in the not so distant future. Thus it is crucial for UiTM and its extensive branch campus network to brace itself for the new challenges facing the global academic and professional community which necessitate mastery of English as the world's 'lingua franca', and the development of social communicative skills. In this respect, UiTM has laid down the necessary groundwork to ensure that it produces future graduates who are not only competent in their subject matter, but also highly-skilled communicators, possessing a high level of oral proficiency, and being able to function conversationally in any context. A majority of current students in UiTM completed both their primary and secondary education in the national language, Bahasa Melayu (Malay). They have also gained formal exposure to English for ten or more years prior to their tertiary education. These are students who are the products of an English language curriculum that places emphasis on communicative skills, meaning the majority of them do possess some general proficiency in the language. Despite their years of exposure to English, many of them do not fall into the category of a reasonably proficient user of English, much less a highly-proficient one. Even though they may achieve reasonably 'high' overall scores, ranging from B to A- in their semester exams for English, there still remains much to be desired with respect to their real performance in the oral domain, i.e., the aspect of oral proficiency.

Young (1995) defines oral proficiency as the "ability to speak the language in a skilled way based on several components which are categorized under communicative competence." Communicative competence according to Sheng (2000) is knowledge that students have to acquire in order to be proficient in the language. Gaudart (2003) defines oral proficiency as the ability to handle with confidence, accuracy, clarity and precision, a large number of communicative tasks; to participate in most informal and formal exchanges on a variety of concrete and familiar topics, to narrate and describe all major uses. Finally Jernigan (2007) refers to oral proficiency as the ability of a speaker to use the language appropriately in given contexts for spoken communication. In addition, Scarcella and Oxford, (1992) said that effective speakers have a variety of abilities which include grammatical competence, strategic competence, sociolinguistic competence and discourse competence. This study, however, will only look at grammatical competence. Savignon (2001) also defines grammatical competence as sentence level grammatical forms, the ability to recognize the lexical, morphological, syntactic, and phonological features of a language and to make use of these features to interpret and form words and sentences. To Savignon, grammatical competence is not linked to any single theory of grammar and does not include the ability to state rules of usage. In other words, one demonstrates grammatical competence by using a rule in the interpretation, expression, or negotiation of meaning.

Oral proficiency in English has always been the benchmark of language proficiency, and the Malaysian Ministry of Education has over the years made repeated calls to teachers to improve the standard of English among students especially with regard to oral proficiency. Hymes (1971) who coined the term 'communicative competence' stated that knowing a language is more than just knowing its grammar. He further stated that there are culturally specific rules of use which relate the language used to features of the communicative contexts. For example, the ways a person speaks or writes to communicate to close friends may not be the same as those used to communicate with professionals. One of the recent measures taken is the conversion of the medium of instruction used in the teaching of mathematics and science, from Malay to English in all national schools. In the context of UiTM's language teaching curriculum, efforts to enhance students' oral proficiency are implemented through various language proficiency-based and ESP courses. The primary objective of this research is to determine the level of oral proficiency of final semester first degree students in UiTM Samarahan, Sarawak by focusing on grammatical accuracy. Cummins (1994), however, cautioned that just being able to talk socially is insufficient. The necessary skill needed is 'Cognitive Academic Language Proficiency' which takes much longer than basic interpersonal communication to develop, which is usually about 5 to 7 years. Cognitive Academic Language Proficiency skills are those that are necessary for literacy obtainment and academic success. It enables students to have academic, analytical conversation and to independently acquire factual information. The learner can use the information to make relationships, make inferences and draw conclusions (Cummins, 1994). Thus, producing effective speakers who are able to use the language for personal communication as well as for academic attainment is the expected and intended outcome of communicative competence. Errors made by learners give us better insights into the process of language learning and they are now regarded as a very important tool for diagnostic purposes in language teaching. Maros et al. (2007) conducted a study on the interference effect of Malay on essays written in English by form one students in Malaysia. Their findings show that despite having gone through six years 
of learning English in school environment, the learners are still having difficulty in using correct English grammar in their writings. Botley et al (2005) also provided support for the value of learner data when they identified a number of systematic effects of 'language transfer' (Odlin, 1989) in a corpus of argumentative essays written by university-level students in Sarawak and Sabah, Malaysia.

The main purpose of this study is therefore to investigate the level of oral proficiency among a sample of final semester first degree students in UiTM Sarawak, Kota Samarahan Campus, by focusing on grammatical accuracy, particularly grammatical errors that are made in the course of an oral discussion task. The specific objectives of the study are three-folds, namely (a) to provide empirical data on students' oral performance and communicative ability, particularly grammatical accuracy at tertiary level, (b) to investigate the students' level of grammatical accuracy in terms of a wide range of grammatical features such as verb tense, noun number, subject-verb-agreement and others, and (c) to derive statistical data on the students' grammatical accuracy from a mini-corpus of oral discussion transcripts.

\section{Methodology}

\subsection{Sampling design}

The sample utilized in this study comprised 20 randomly-selected final year students from the Accountancy and Administrative Science faculties at UiTM's Samarahan campus near Kuching, Sarawak. A purposive sampling technique was employed in selecting the sample for this study. A complete list of all the final semester degree students from the Accountancy, and Administration Science was obtained from the respective Heads of Program.

\subsection{Instrumentation}

All the 20 students were placed into five different groups comprising four members, and asked to participate in a group discussion task in English. The group discussions followed the MUET speaking format with minor adjustment in terms of duration. All the groups were given the same topic on current issue for discussion. The students were asked to undergo two stages of the discussion. In the first stage, the students made individual presentations based on the selected stimulus, and in the second stage they were asked to discuss in groups the stimulus presented. See Appendix A for details of the stimulus used for the group discussions.

The entire group discussions were tape recorded and orthographically transcribed verbatim to provide the mini-corpus used in this study. Afterwards, the transcripts were subjected to a detailed error analysis using the UCL Error Editor (Dagneaux et al., 1998). This software is used to manually analyze the grammatical errors by general category. The Editor makes use of a detailed error typology which allows errors to be classified into a number of mainly lexical and grammatical categories.

Using the UCL Editor to select a category from an onscreen menu, the analyst can use the computer to automatically insert a 'tag' or code into the soft copy of the transcript, along with an indication of the target word or phrase. The Error Editor recognizes several error domains such as $\mathbf{G}$ (grammatical, $\mathbf{L}$ (lexical), $\mathbf{X}$ (lexico-grammatical) $\mathbf{F}$ (formal), $\mathbf{R}$ (register), $\mathbf{W}$ (syntax) and $\mathbf{S}$ (stylistic). These codes can be combined together and with others to form error tags. A full list of the error tags is included in Appendix B below, and Appendix C shows an extract from one of the tagged transcripts. For instance, errors involving singular or plural nouns can be tagged GNN (Grammatical Noun Number). The tag, in parentheses, precedes the error, and a suggested target, enclosed in ' $\$ \$$ ', can be inserted afterwards, as in the following example from our corpus: Because for me the, the public. They have so many (GNN) burden \$burdens\$ (Transcript 1). Finally, in order to obtain statistics concerning the distribution of error categories in the five transcripts analyzed, the Wordsmith Tools concordance software (Scott, 1996) was used to count the error tags in each transcript. The numerical data was then tabulated, as will be seen below.

\section{Results and discussion}

\subsection{Transcript analysis}

The data analyzed in this study consisted of five oral discussion transcripts. The composition of these transcripts in terms of wordage is shown in Table 1. To obtain these counts, only the utterances made by the students were counted, and the header information, and utterances made by the researchers, was excluded. The word count also includes repeated words, and fillers such as 'ah' or 'erm', as these are considered important for the objectives of this study. Now that we have shown the number of words in the sample, let us look at the distribution of errors, in order to provide some insights into the extent of oral and grammatical competency of the students under analysis.

Table 2 below shows the frequency scores for all of the error categories, realized as error tags, identified in the five transcripts. The figures are shown for each transcript for completeness (Columns 2 to 6), but no attempt is made in this analysis to compare transcripts, as there is not enough data to make statistically meaningful comparisons at this stage. Note that the raw scores in bold type in Column 7 are supplemented by the normalized frequency scores per 1000 words (Note 1), in bold in Column 8 on the right, in order to give a slightly sharper picture of the distribution of the most common error categories. Furthermore, please note that the grey bar in the middle of the table marks a cut-off point 
of $>=10$ errors, to distinguish the most frequent error categories more clearly from the least frequent ones. Table 2 reveals many observations about the grammatical errors made by the students in our study. The first thing we can say is that fairly basic grammatical errors, such as noun number (GNN), lexical choice (LS), subject-verb agreement (GVN) and verb tense (GVT) are among the most common errors identified in the five transcripts.

Let us illustrate this with some examples from the transcripts.

(2) We have all know that the prices of basic (GNN) necessity \$necessities\$ such as food have been increasing.

(3) Believe that we have known the (LS) task \$reason\$ why we are here today

(4) Because all of this food necessity $(\mathrm{GVN})$ are $\$$ is $\$$ controlled by the government

(5) Then they should (GVT) caught $\$$ catch $\$$ them and whichever like that

This is in line with the generally-held perceptions of members of the research team, and also reflects findings from Botley et al's (2005) work on a large corpus of UiTM student essays, where these classes of error were among the most frequent, especially GNN and GVT. However, one interesting observation is the high frequency of WM (missing word) and WR (redundant word) errors identified in this data. Here are some examples to illustrate:

(6) The government also should (WM) \$be\$ more strict in taking actions against the sellers

(7) The workshop (WR) it \$0 \$ should contain (WM) \$a session\$ about how to spend accurately

(8) They just (WR) buy buy \$buy \$ it.

These three examples illustrate the common phenomenon of missing out words or other sentence fragments from the utterances. The suggested targets are of course those judged as appropriate by the analyst, which introduces an element of subjectivity which is unavoidable in this kind of analysis.

When it comes to the examples of redundancy, these examples show two kinds of redundancy commonly identified in the data. The first kind is simple inclusion of material that adds nothing to the meaning of the utterance, or that which may fall into the category of 'overuse', as with example (7). The second class of redundancy is simple repetition of words or phrases, which is most likely evidence of nervousness or the use of an online self-repair strategy of the kind commonly found in spoken data (Biber et al, 1999). Therefore, to sum up at this stage, the data reveals that many basic grammatical and lexical errors are very frequent in the data. These error categories are of the kind that should in theory have been ironed out during the normal course of a decade's worth of formal English language instruction.

Furthermore, if we look at the normalized scores per 1000 and 100 words, we can see this in stark detail. Table 3 below shows that the 979 errors identified in the 8,326 words of the sample translates to 117.58 errors per 1,000 words, and 11.76 errors per 100 words. We can also extrapolate from this that on average, there are almost 196 errors per transcript, more than 120 errors per 1000 words and just over 12 errors per 100 words. This adds up to a seriously high rate of errors identified in a relatively small corpus of 8,326 words and just five transcripts.

\subsection{Communicative ability}

Now that we have drawn a picture of the grammatical competence of the students under analysis, we will finish this section with some comments about the communicative abilities of the students, as displayed in the transcripts. The previous section provided some evidence of performance phenomena that are most likely spawned from the spoken, online nature of the interactions being studied, for instance the high frequency of redundancy, and missing words in the data. However, how did the students fare as fluent communicators? One thing that emerges from the transcripts is a preponderance of dysfluency, hesitation phenomena, self-repair and incomplete utterances of the kind discussed in detail in Biber et al (1999:1052-1066), and which are commonly found in spoken discourse.

Biber et al. (1999: 1048) pointed out that, because spoken language takes place in real time, placing limitation on the memory of a speaker, there is a need for speakers to plan their utterances online, in effect as they are going along. This would explain the apparently messy, incomplete and hesitant nature of spoken transcripts at first glance, which distinguishes such data sharply from more well-planned and structured written discourse. In the data analysed in this paper, there is plenty of evidence of the kinds of performance phenomena described by Biber et al in their excellent account of the grammar of spoken English conversations. We will discuss the most obvious and seemingly common examples below.

(a) Hesitations.

Here are some examples of hesitation, taken from Transcript 1, with the phenomena in question rendered in italics. As we see, there is an overlap with repetition and in many cases, what is tagged as WR can also be seen as hesitation: A very good afternoon to all of you and to the examiner. As for my, as for my topic, it is to suggest the government control the prices of basic food items which is the best way to keep food prices down. And thirdly is, the rate poverty index is 
still high in our country, so we should know that the income of families in our country is still, is still far from, is still far from the rich.

(b) Filled pauses

Here, a speaker often uses verbal fillers such as 'ar' or 'em', as we can see from this long extract with many examples of such filled pauses: this is because, first, basically because objective of having such workshop is to educate the consumer on how to save money and spend wisely...ar.. and then..ar... beside that ar...through workshop em... ar.. the consumer association can give information, the dos and don'ts ar... in order to, to...but I mean, for example buy necessary, buy necessary things instead of er... buying unuseful things. Ar... for example, ar..., example, the consumer should buy em... the necessities such as rice, vegetables, that is, that is for the specific period. For instance, ar... if the person ar... if the person ar... is to purchase too much vegetables, maybe they are certain period, the vegetables will get... will get.... will get...will get...ar... unfresh... or cannot be, cannot be eat, cannot be use or cook.

(c) Repeats and reformulations.

Some examples of repetitions are tagged as redundant utterances in the previous section. However, according to Biber et al (ibid), many examples of repeats reveal a speaker starting an utterance only to start it again in a different form, as we see in these examples: The side effect of this plant a... this campaign where the after..ar evening they make gardening, so this can make they more healthy. So you know that the public will, I mean they will agree to the policy presented, presented by the government. Here, a speaker self-repairs while he or she is speaking, in effect reformulating or repeating what he or she is planning to say. This is done because the speaker does not have the time to formulate a complete idea in real time. The level of grammatical accuracy manifested in the students' oral performances, can also be answered clearly and definitively by stating that the level of grammatical accuracy seems to be quite low, at least if we measure this by frequency of errors. There are certainly some students in the sample who manifested fewer errors than the others, but on average, the data reveal a desperate need on the part of the students to undergo further remedial help on basic grammatical rules and structures in English. The state of the students' communicative ability is harder to answer definitively based on the data analyzed. However, we can say that despite the presence of the usual array of performance dysfluencies in the data, there is evidence that the students know how to communicate in groups fairly effectively, follow the rules of turn-taking and generally speak on their given topic with a good level of relevance. This is a tribute to the formal nature of the situation they are in and to the training they would have received by their lecturers. However, more work clearly needs to be done, on a larger number of students, before we can make any concrete statements concerning the communicative abilities of UiTM graduating students.

To sum up, we can see that the transcripts show plenty of evidence of the linguistic and communicative 'messiness' usually found in spoken discourse. However, this is hardly surprising given that, firstly, the speakers are forced to plan and often to re-plan their utterances in real time, secondly, they are being subjected to a stressful examination situation and thirdly, all of them are non-native speakers of English. All of these restrictions place a serious load on the speakers' memories and cognitive capacities, which would not be the case if the students were writing essays.

In the students' favour, the transcripts do show that the speakers are fully aware of the basic rules of conversation, including turn-taking, which is in evidence here. In fact, this analyst experienced some surprise at the seeming lack of interruption phenomena and overlaps often identified in spoken conversations. This may be the result of the rigid, highly structured nature of the task, in which the students had to firstly give an individual presentation of their case, and secondly had to participate in a four-way discussion. Also, there may be cultural reasons why students do not interrupt their peers, and perhaps their lack of confidence may also play a part.

Our study was delimited to studying only students' actual or current level of oral proficiency in terms of grammatical accuracy involving a small sample of student population, i.e. 20 final semester Bachelor degree students in UiTM Sarawak. The mini-corpus comprises five oral discussion transcripts, and the total number of words in the corpus is 8,326 words. This relatively small sized sample may affect the external validity of any conclusions arising from this research. We are aware that a more in-depth study could be conducted in the future to ascertain factors which affect students' oral proficiency and how these factors influence different groups of L2 learners. However, we believe that the small number of students can still provide sufficiently relevant pilot data to yield significant findings on the students' level of oral proficiency and grammatical competence and the findings will therefore have some internal validity.

\section{Conclusions}

This paper set out to derive empirical data on UiTM students' oral performance, particularly grammatical accuracy and communicative ability. This was carried out by a detailed computer-aided analysis of a mini-corpus of oral discussion transcripts using an existing typology to classify grammatical and lexical errors into different categories. Therefore, it can be said that we have achieved all of the objectives set out above in Section 1.4. As for our research questions, we have shown that the most frequent grammatical errors made by students seem to be the most basic, and most anticipated 
errors such as noun number, subject/verb agreement and verb tense, and that these are the very categories that Malaysian students often have difficulty with, given the structure of the L1, Bahasa Malaysia.

Another finding was the high preponderance of performance-related errors such as missing words and word strings, as well as various redundancies and performance phenomena such as repeats and reformulations. These may or may not be due to the spoken, online nature of the speech situation, which is common to all spoken discourse where the speaker does not have the time or memory capacity to plan utterances properly. However, it may be speculated that the high frequency of WM errors - where words or strings are missed out from an utterance or clause - may be related to the learners' interlanguage (Selinker, 1972), or the state of their knowledge of the L2. We would require further research to arrive at more concrete conclusions on this matter.

Finally, it would appear that the problems, where they occur, are not with communicative ability per se, but rather with grammatical competence and particularly grammatical accuracy. It is hoped that these findings will show the way toward better and more effective ways of improving the grammatical ability of UiTM students of English, so that the error counts in future research of this kind can fall towards zero.

It is recommended that $\mathrm{n}$ order to enhance the learners' grammatical competence as far as oracy is concerned; they should be given ample opportunity to use, produce and practise English structures or sentences through simulated situations. This can be done by getting them involved in various immersion activities in class and outside the classroom. Another objective of having these activities is to build the students' confidence in using the language. English language classes should immerse the students in the language-based activities such as presentations, group discussion, open discussion, debates and drama. They should also be encouraged to carry out activities outside the classroom such as conducting interviews and gathering information for documentaries. Last but not least, it would be for teachers to introduce consciousness-raising techniques to sensitize learners to the various forms and meanings of structures used in everyday conversation in English. Reducing teacher-student ratios in English language classes may also help to improve focus and concentration during the learning process.

\section{References}

Biber, D., Johansson, S., Leech, G., Conrad, S. and Finegan, E. (1999). The Longman Grammar of Written and Spoken English. Harlow: Addison-Wesley Longman.

Botley, S. P., Haykal Hammaad Zin and Monaliza Bt. Sarbini. (2005). 'Lexical and Grammatical Transfer by Malaysian Student Writers', In the Proceedings of the 10th International Conference on Translation, Universiti Malaysia Sabah, Kota Kinabalu, 2nd - 4th August 2005.

Cummins, J. (1994). Second Language Acquisition: The Language Learning Theories of Professor J. Cummins:http://www.fis.edu/esweb/esl/teachrs/support/cummin.html Accessed: 13 February 2008

Dagneaux, E, Denness, S. and Granger, S. (1998). Computer-aided error analysis. System. An International Journal of Educational Technology and Applied Linguistics, 26(2), 163-174.

Gaudart, H. (2003). English Language Teaching Practice. Sasbandi-Melta Series, Sasbadi Sdn. Bhd.

Hymes, D. (1971). On Communicative Competence. University of Pennsylvania Press. Pennsylvania. In Guy Cook (2007). Applied Linguistic. Oxford University Press.

Jernigan, J. (2007). 'Assessing ELL Oral Proficiency: Issues and Recommendations'. Sunshine State. TESOL Journal. Vol. 6. Number 1.

Maros, M., Tan Kim Hua \& Khazriyati Saluhiddin. (2007). Interference in Learning English: Grammatical Errors in English Essay Writing Among Rural Malay Secondary School Students in Malaysia. Jurnal e-Bangi. Jilid 2, Bil 2. Jan-Disember.

Odlin, T. (1989). Language Transfer: Cross-linguistic influence in language learning. Cambridge: Cambridge University Press.

Savignon, S. J. (2001). Communicative Language Teaching for the Twenty-First Century. In Teaching English as a Second or Foreign Language. Third Edition.Marianne Celce-Murcia, Editor. Heinle \& Heinle. Thomson Learning, Inc. USA.

Scarcella, R. C. \& Oxford, R. L. (1992). The Tapestry of Language Learning: The Individual in the communicative classroom. Heinle \& Heinle Publishers. Boston, Massachusetts. USA.

Scott, M. (1996). Wordsmith Tools. Oxford: Oxford University Press.

Selinker, L. (1972). 'Interlanguage'. International Review of Applied Linguistics, 10:209-31.

Sheng $\mathrm{Xu}$ Li. (2000). Strategic Competence for Intercultural Communication: http://www.mhle.com/SOCScience/foreign lang/conf/grammar.htm. Accessed 10 February 2007. 
Young, R. (1995). 'Conversational Style in Language Proficiency Interviews'._Language Learning Journal. Vol. 45:1, $3-42$.

Table 1. Word Counts

\begin{tabular}{|l|l|}
\hline Transcript & $\begin{array}{l}\text { Number of } \\
\text { Words }\end{array}$ \\
\hline T1 & 1786 \\
\hline T2 & 1271 \\
\hline T3 & 1733 \\
\hline T4 & 1972 \\
\hline T5 & 1564 \\
\hline TOTAL & $\mathbf{8 3 2 6}$ \\
\hline
\end{tabular}

Table 2. Error Frequencies in Group and Individual Presentations

\begin{tabular}{|c|c|c|c|c|c|c|c|}
\hline Tag & $T 1$ & $T 2$ & T3 & T4 & T5 & $\begin{array}{l}\text { Raw } \\
\text { TOTAL }\end{array}$ & $\begin{array}{l}\text { TOTAL Per } \\
1000 \text { words }\end{array}$ \\
\hline GNN & 27 & 26 & 41 & 55 & 26 & 175 & 20.87 \\
\hline WM & 14 & 28 & 43 & 43 & 47 & 175 & 20.87 \\
\hline WR & 40 & 11 & 25 & 40 & 44 & 160 & 19.22 \\
\hline $\mathrm{LS}$ & 24 & 13 & 24 & 41 & 28 & 130 & 15.61 \\
\hline GVN & 23 & 15 & 10 & 13 & 16 & 77 & 9.25 \\
\hline GVT & 8 & 2 & 14 & 14 & 17 & 55 & 6.61 \\
\hline GA & 10 & 0 & 6 & 13 & 6 & 35 & 4.20 \\
\hline GP & 7 & 8 & 6 & 9 & 2 & 32 & 3.84 \\
\hline $\mathrm{S}$ & 0 & 0 & 9 & 6 & 7 & 22 & 2.64 \\
\hline $\mathrm{WO}$ & 6 & 0 & 1 & 2 & 9 & 18 & 2.16 \\
\hline GWC & 1 & 0 & 7 & 6 & 4 & 18 & 2.16 \\
\hline FS & 4 & 5 & 4 & 4 & 0 & 17 & 2.04 \\
\hline LP & 2 & 0 & 2 & 8 & 0 & 12 & 1.44 \\
\hline FM & 1 & 2 & 3 & 0 & 2 & 8 & 0.90 \\
\hline $\mathrm{R}$ & 0 & 0 & 5 & 0 & 2 & 7 & 0.84 \\
\hline GNC & 1 & 0 & 0 & 0 & 4 & 5 & 0.60 \\
\hline LSF & 0 & 0 & 3 & 0 & 2 & 5 & 0.60 \\
\hline SU & 0 & 1 & 0 & 2 & 1 & 4 & 0.48 \\
\hline XVPR & 0 & 2 & 1 & 0 & 1 & 4 & 0.48 \\
\hline SI & 1 & 0 & 0 & 0 & 2 & 3 & 0.36 \\
\hline XVCO & 1 & 0 & 0 & 2 & 0 & 3 & 0.36 \\
\hline XNPR & 0 & 1 & 0 & 0 & 1 & 2 & 0.24 \\
\hline GVM & 0 & 0 & 0 & 1 & 1 & 2 & 0.24 \\
\hline LCS & 0 & 0 & 0 & 0 & 2 & 2 & 0.24 \\
\hline GADJCS & 1 & 0 & 0 & 0 & 0 & 1 & 0.12 \\
\hline GADVO & 1 & 0 & 0 & 0 & 0 & 1 & 0.12 \\
\hline XADJPR & 1 & 0 & 0 & 0 & 0 & 1 & 0.12 \\
\hline GADJ0 & 0 & 0 & 1 & 0 & 0 & 1 & 0.12 \\
\hline GVAUX & 0 & 0 & 0 & 1 & 0 & 1 & 0.12 \\
\hline LCLS & 0 & 0 & 0 & 1 & 0 & 1 & 0.12 \\
\hline $\mathrm{XNCO}$ & 0 & 0 & 0 & 1 & 0 & 1 & 0.12 \\
\hline GVV & 0 & 0 & 0 & 0 & 1 & 1 & 0.12 \\
\hline $\begin{array}{l}\text { TOTAL } \\
\text { ERRORS }\end{array}$ & 173 & 114 & 205 & 262 & 225 & 979 & 117.58 \\
\hline
\end{tabular}

Key:

FM: formal/morphological error, FS: spelling error, GA: Article misuse, GADJCS: Adjective error, GADVO: Adverb error, GNC: Genitive/possessive error, GNN: Noun Number error, GP: Pronoun misuse, GVAUX: error involving 
auxiliaries, GVM: verb morphology error, GVN: Subject Verb Agreement (Number Concord), GVT: Verb Tense error, GVV: Error involving passive/active voice, GWC: wrong word class, LCLS: logical connector error, LCS: Subordinating Conjunction error, LP: lexical phrase misuse, LS: Lexical choice, S: Style (foreign-sounding or garbled utterance), SI: Style (incomplete utterance), SU: Style (unclear utterance), WO: Wrong word order, WR: Redundant word/string, WM: Missing word(s), XADJPR: adjective complementation error, XNCO: noun complementation error, XVCO: verb complementation error.

Table 3. Normalised, Raw and Average Frequencies

\begin{tabular}{|l|l|l|l|l|}
\hline Transcript & $\begin{array}{l}\text { Number of } \\
\text { Words }\end{array}$ & $\begin{array}{l}\text { Number of } \\
\text { Errors }\end{array}$ & $\begin{array}{l}\text { Errors per } \\
\mathbf{1 0 0 0} \text { words }\end{array}$ & $\begin{array}{l}\text { Errors per } \\
\mathbf{1 0 0} \text { words }\end{array}$ \\
\hline T1 & 1786 & 173 & 98.86 & 9.68 \\
\hline T2 & 1271 & 114 & 89.69 & 8.96 \\
\hline T3 & 1733 & 205 & 118.29 & 11.83 \\
\hline T4 & 1972 & 262 & 132.86 & 13.29 \\
\hline T5 & 1564 & 255 & 163.04 & 16.30 \\
\hline Average & $\mathbf{1 6 6 5 . 2}$ & $\mathbf{1 9 5 . 8}$ & $\mathbf{1 2 0 . 5 5}$ & $\mathbf{1 2 . 0 1 2}$ \\
\hline OVERALL & $\mathbf{8 3 2 6}$ & $\mathbf{9 7 9}$ & $\mathbf{1 1 7 . 5 8}$ & $\mathbf{1 1 . 7 6}$ \\
\hline
\end{tabular}

Notes

Note 1 . Calculated by dividing the raw score by the total number of words in the corpus and multiplying by 1000 . 